\title{
Optimization of the flood protection effect of a hydropower multi-reservoir system
}

\author{
FRÉDÉRIC M. JORDAN, Ecole Polytechnique Fédérale de Lausanne (EPFL), Laboratoire de Constructions \\ Hydrauliques (LCH), Station 18, CH-1015 Lausanne, Switzerland (now at: e.dric.ch, Le grand-Chemin 73, CH-1066 \\ Epalinges, Switzerland)
}

JEAN-LOUIS BOILLAT, Ecole Polytechnique Fédérale de Lausanne (EPFL), Laboratoire de Constructions Hydrauliques (LCH), Station 18, CH-1015 Lausanne, Switzerland

ANTON J. SCHLEISS, Ecole Polytechnique Fédérale de Lausanne (EPFL), Laboratoire de Constructions

Hydrauliques (LCH), Station 18, CH-1015 Lausanne, Switzerland. Email: anton.schleiss@epfl.ch (author for correspondence)

\begin{abstract}
The use of existing hydroelectricity multi-reservoir systems for flood protection may be an efficient approach in many catchment areas. The assessment of the protection potential offered by the hydropower plants during floods requires a comprehensive analysis of the catchment area, including the simulation of flood scenarios. A methodology for the optimization of turbine and bottom outlet operations of multi-reservoir systems during floods is presented. Based on a theoretical catchment configuration, the most relevant parameters in view of reducing of the peak flows in rivers located downstream of the reservoirs are analysed in a systematic way with the help of hydrological forecasts. The influence of the drained areas, the installed turbine capacities, the emergency rules and the location of the reservoirs on the flood control in such a complex catchment area is highlighted. The optimization approach is applied in the Upper Rhone River basin in Switzerland, where 10 major hydropower schemes with large reservoirs are located. The results regarding peak flow reduction at the catchment outlet are in good agreement with the theoretical values obtained with the developed methodology.
\end{abstract}

Keywords: Flood risk management; multi-reservoir systems; preventive operation of hydropower schemes; flood forecast

\section{Introduction}

Hydropower multi-reservoir systems can strongly influence the flood regime in their catchment areas. However, their influences depend on several parameters such as the relative importance of the drained areas, the water storage capacities and the location of the reservoirs within the basin.

Large reservoirs that have a certain storage capacity reserved for flood routing can significantly reduce the peak flow in the downstream rivers during floods (Cheng and Chau 2004). Nevertheless, the protection effect also highly depends on the initial filling rate. If the reservoirs are already full before a flood, obviously no (gated spillway) or limited (ungated spillway) flood routing is possible. To avoid such a situation, inflow forecasts are useful for the determination of the volume to be released before the flood enters the reservoir. The pre-emptying operation of the reservoirs allows to maximize the water storage and consequently to optimize the protection of the downstream river reaches during floods.
The optimal rules for the management of hydropower schemes during floods are often determined with pre-defined scenarios (Jain et al. 1999, Ahmad and Simonovic 2000). The results are fixed operation rules, depending on the inflow and the available storage capacity in the reservoirs. Such rules are mostly focused on dam safety and often non-optimal regarding flood management downstream. In order to improve operation rules, a methodology was developed to highlight and optimize the key parameters controlling the flood protection potential in catchment areas with multi-reservoir systems. The methodology is illustrated on a theoretical catchment model, considering 10 hydropower schemes having similar characteristics. Based on a hypothetical realized hydrological forecast, an optimization procedure of the operations of the reservoirs is proposed. Since weather forecasts have intrinsic uncertainty, the optimization has to be updated continuously with every new forecast available. With the developed procedure, the most efficient reservoir operations can be obtained, while maintaining the multiobjective goals of reducing peak flood flows in downstream 
regions during floods without economic loss of energy production (Jordan 2007). The used pre-emptive goal programming optimization algorithm is not presented in this contribution. Further information can be found in literature (Yeh and Becker 1982, Yeh 1985, Eschenbach et al. 2001, Labadie 2004).

Numerous important multi-reservoir systems and natural lakes are situated in the Alps. Recent floods have caused severe damages in these Alpine catchment areas with a dense urbanization in the lower alluvial valley regions. As in numerous regions in the world (De Roo et al. 2003, Turcotte et al. 2004), there is also a strong need for flood management systems in these Alpine regions (Buergi 2002, Drabek et al. 2002, Rezler et al. 2006). In the Rhone River basin upstream of Lake Geneva, several hydropower schemes with large reservoirs are located. A new model for flood prediction and management of the Rhone River basin was developed, called MINERVE (Raboud et al. 2001, Boillat et al. 2002, Boillat 2005). A flood forecast system was implemented, which allows the prediction of the discharges within a semi-distributed numerical model for a $72 \mathrm{~h}$ lead time (Schaefli et al. 2005). Furthermore, a new optimization tool was implemented in this flood prediction model in order to identify the optimal operations of the reservoirs before and during floods (Jordan et al. 2005, 2006a, 2008). As an example, the flood event of October 2000 is simulated and compared with the proposed methodology with the purpose to highlight the flood protection potential of existing multi-reservoir systems.

\section{Methodology for the operation of a multi-reservoir system}

\section{Optimization problem}

In catchment areas with large hydropower reservoirs, the risk related to flood events not only depends on the hydrological processes, but also on the operation of the present hydropower plants (HPPs). The protection effect of the HPPs is optimal when the entire inflow into the reservoir is stored and the outflow limited to zero. For such conditions, the stored inflow reduces the flood hydrograph downstream in the main valley. Thus, an optimal reduction of the peak flow can be obtained at critical locations along the water courses.

With insufficient storage capacity in the reservoir, the emergency operating rules of the dams force the operator to release water through the turbines or the gated spillways. These emergency rules of the reservoir are often in contradiction with the optimal operation for the reduction of the peak flow downstream. If the hydropower schemes are operated during the passage of the flood peak in the main valley, the situation can be worsened. Such undesirable situations can be avoided with the help of discharge forecasts, which can predict the probable future reservoir inflow and compare it with the available storage volume. When the probable inflow exceeds the available storage volume, opening of the turbines or bottom outlets before the flood peak can increase the retention capacity of the reservoir and limit the water releases during the peak flow in the main valley.
As an objective function, the minimization of the costs of damages in the entire catchment area during floods was used (Jordan et al. 2006b, Jordan 2007). The cost of damages depends upon the differences between the flood peak and the discharge capacity of the river. Furthermore, the costs related to energy sales loss when bottom outlets are opened or turbines have to be operated at low energy demand are also considered. In any case, the optimization goal is to have full reservoirs again at the end of a flood event.

The start and stopping times of the turbine operations are the optimization variables for every HPP. Since turbines should be operated as soon as possible in order to create a sufficient storage volume, their start time is set to zero in the optimization procedure after a flood alert.

\section{Layout of the idealized catchment area}

In order to identify the key parameters influencing the flood protection potential by preventive reservoir operations before the flood peak, an idealized catchment area containing 10 hydropower schemes with large reservoirs is studied. The hydropower schemes are assumed to be regularly distributed in parallel along the main river (Figure 1) as it is mostly the case in alpine valleys.

All parameters of the hydropower schemes and their subcatchments are identical. In particular, the rainfall is supposed to be uniform in the entire catchment area, the sub-catchments have the same surface, river topology and soil characteristics. The inflows into the reservoirs are equal regarding time offset, amplitude and shape. All 10 reservoirs have the same rating curves, initial filling rates before the flood, installed turbine capacity and gated spillway characteristics and emergency rules. The ideal catchment area with the layout of the 10 similar hydropower schemes is shown in Figure 1. Each hydropower scheme has a specific drained area, a reservoir

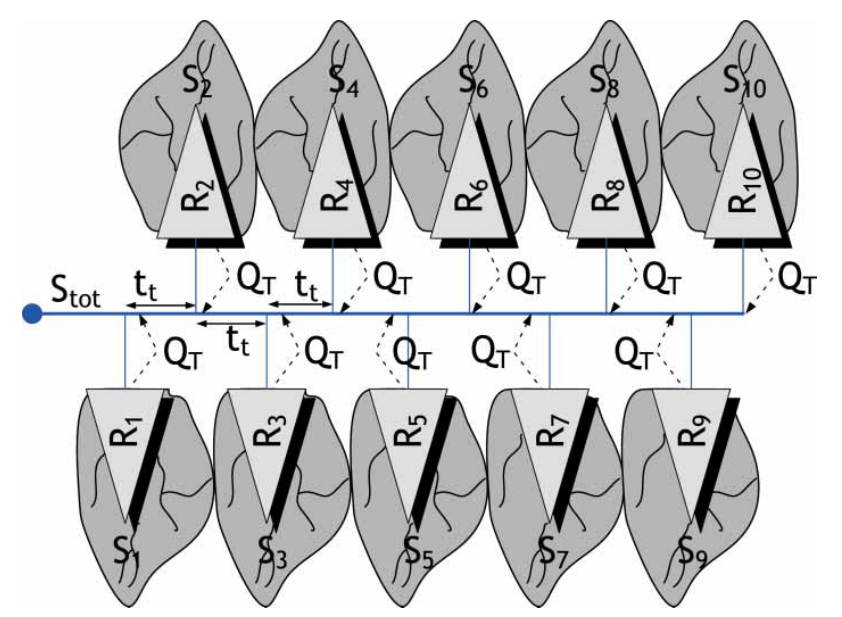

Figure 1 Layout of the idealized catchment area containing 10 hydropower schemes with large reservoirs located in lateral valleys. $S_{\text {tot }}$ is the total area at the outlet of the catchment area, $S_{1}-S_{10}$ are the sub-catchment areas of reservoirs $R_{1}-R_{10}, t_{\mathrm{t}}$ is the transit time between two junctions and $Q_{\mathrm{T}}$ is the turbine capacity. 
Table 1 Values of the model parameters for the ideal catchment area.

\begin{tabular}{llc}
\hline Parameter & \multicolumn{1}{c}{ Description } & Value \\
\hline$S_{\text {tot }}$ & Total surface of the catchment area & $10,000 \mathrm{~km}^{2}$ \\
$V_{\text {tot }}$ & Total volume of precipitation & $108 \mathrm{~mm}$ \\
$\mathrm{Cr}$ & Runoff coefficient & 0.33 \\
$D$ & Duration of the flood event & $72 \mathrm{~h}$ \\
$V_{\text {res,tot }}$ & Total storage volume of one reservoir & $100 \mathrm{Mio} \mathrm{m}^{3}$ \\
$S_{\text {res }}$ & Water surface of a completely filled & $2 \mathrm{~km}^{2}$ \\
& $\quad$ reservoir & $100 \%$ \\
$F_{\mathrm{R}}$ & Initial filling rate of the reservoirs & \\
\hline
\end{tabular}

including a free surface crested spillway and a power shaft with a high head powerhouse located next to the main river.

\section{Typical parameters and variables}

The studied idealized catchment area could be the same at different scales. However, the numerical values of the parameters and variables were chosen to be comparable to the specific scale of the Rhone River basin upstream of Lake Geneva. The typical values of the model parameters are presented in Table 1.

The flood characteristics are not computed by a rainfall-runoff model. The hydrograph at the catchment outlet is obtained by scaling the shape of a typical hydrograph observed during the 1993 flood event at the Upper Rhone River basin outlet. A relationship is used which forces the volume of the hydrograph to be similar to the net precipitation.

$$
\int Q_{\mathrm{tot}}(t) \mathrm{d} t=V_{\text {tot }} \cdot \mathrm{Cr}
$$

where $Q_{\text {tot }}(t)\left(\mathrm{m}^{3} / \mathrm{s}\right)$ is the discharge at the catchment outlet. As an appropriate value of $Q_{\text {tot }}$, the shape of the hydrograph presented in Figure 2 is used. This normalized discharge $Q_{\text {norm }}(t)$ is then multiplied by a coefficient $\beta$ (Eq. 2)

$$
Q_{\text {tot }}(t)=\beta \cdot Q_{\text {norm }}(t) \text {. }
$$

The chosen capacity of one reservoir corresponds to $278 \%$ of the volume of the net precipitation. However, the reservoirs are

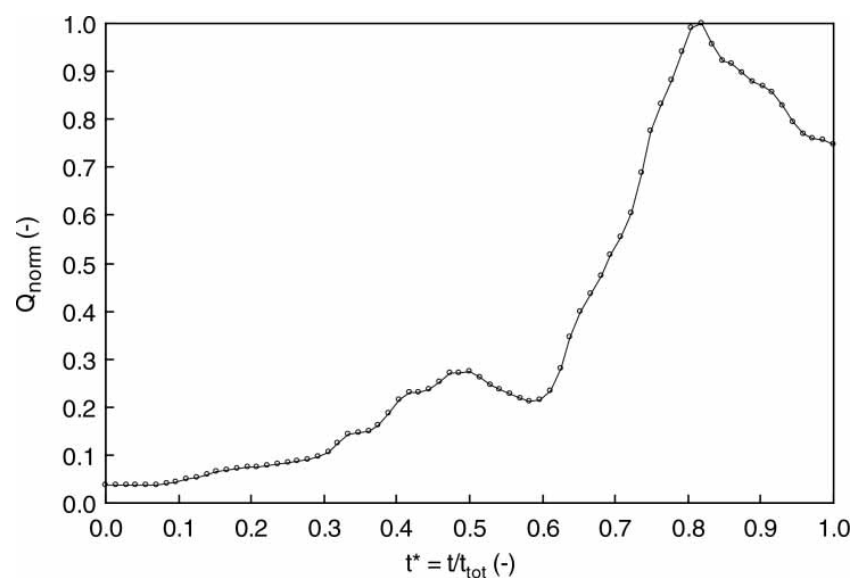

Figure 2 Shape of the normalized hydrograph.
Table 2 Studied range of the model variables of the ideal catchment area.

\begin{tabular}{llcc}
\hline Variable & \multicolumn{1}{c}{ Description } & Range & Ratio \\
\hline$S_{i}$ & Drained surface of 1 & $50-800 \mathrm{~km}^{2}$ & $0.005-0.08$ \\
& reservoir & $\left(V_{\text {tot }}\right)$ \\
$Q_{\mathrm{T}}$ & Turbine capacity & $0-200 \mathrm{~m}^{3} / \mathrm{s}$ & $0-0.064$ \\
& & & $\left(Q_{\text {tot, max }}\right)$ \\
$B$ & Width of the spillway & $10-150 \mathrm{~m}$ & - \\
$T_{\mathrm{t}}$ & Transit time between & $0-6 \mathrm{~h}$ & $0-083(D)$ \\
& $\quad$ junctions & & \\
\hline
\end{tabular}

assumed to be filled at the beginning of the flood event. Furthermore, the routing capacity of the reservoirs depends on the reservoir rating curve. In this study, a value of $2 \mathrm{Mio}^{3}$ for a $1 \mathrm{~m}$ water level increase is used.

The analysed system is characterized by four variables (Table 2). The drained surface of every reservoir is the most important variable of the multi-reservoir system, which varies from $0.5 \%$ to $8 \%$ of the total surface of the catchment area. Consequently, the total drained surface is $5-80 \%$ when considering 10 reservoirs. Another important variable is the installed turbine capacity, which varies from 0 to $200 \mathrm{~m}^{3} / \mathrm{s}$. Such values are typical for high head HPPs. When all powerhouses operate simultaneously, up to $64 \%$ of the maximum considered flood peak discharge $Q_{\text {tot,max }}$ is released into the main river. The width of the crested free surface spillway of each reservoir varied from $10 \mathrm{~m}$ (high-retention capacity during floods) to $150 \mathrm{~m}$ (lowretention capacity). Finally, the transit time between junctions was also analysed. Thus, the spatial distribution of the hydropower schemes inside the catchment area was considered. Low-transit time indicates that all reservoirs are close to each other and situated near the catchment outlet.

\section{Effect of the multi-reservoir system on the reduction of the peak flow in the main river}

The effect of the multi-reservoir system on the flood protection of the valley was analysed by varying the four model variables presented in Table 2. In order to clearly highlight the absolute protection potential of the whole system, numerous parameters were kept constant. For example, a uniform spatial distribution of the rainfall was assumed. Furthermore, the initial conditions of all hydropower schemes were similar. This allowed avoiding special conditions, such as local heavy rainfall in the basin of a reservoir with a low initial filling rate which produces no discharge into the main river. A more realistic approach could have been the stochastic generation of rainfall series and initial model conditions. Nevertheless, with simplified model parameters, the flood protection potential of the multi-reservoir systems could be illustrated better.

In the following analysis, the drained surface of each reservoir is systematically varied. For comparative reasons, the ratio between 
the maximum discharge at the catchment outlet and the maximum discharge without hydropower schemes is used as an indicator.

The optimization is done in a deterministic fashion. The future inflows are supposed to be perfect forecasts, which mean that there is no uncertainty associated with any flood scenario. In reality, the forecasts are never perfect and the optimized operations have to be determined considering the uncertainty of the forecast. The uncertainties can be strongly limited by updating the optimized operation with any new forecast available (typically every $12 \mathrm{~h}$ ).

\section{Optimization example of a flood scenario}

The optimal use of the multi-reservoir system is illustrated with an example of a flood scenario in Figure 3. The hydrographs used are derived from the flood of October 2000 in the catchment outlet of the Upper Rhone River. The normalized used variables $Q_{\mathrm{T}}^{*}, Q^{*}, T_{\mathrm{t}}^{*}$ and $S^{*}$ are defined in Eqs. (3)-(6):

$$
Q_{\mathrm{T}}^{*}=\frac{Q_{\mathrm{T}}}{Q_{\max }},
$$

where $Q_{\mathrm{T}}\left(\mathrm{m}^{3} / \mathrm{s}\right)$ is the installed turbine capacity and $Q_{\max }\left(\mathrm{m}^{3} / \mathrm{s}\right)$ the maximum discharge at the catchment outlet without the influence of the reservoirs.

$$
Q^{*}=\frac{Q_{\mathrm{tot}}}{Q_{\max }}
$$

where $Q_{\text {tot }}\left(\mathrm{m}^{3} / \mathrm{s}\right)$ is the maximum discharge at the catchment outlet considering the optimal influence of the reservoirs.

$$
T_{\mathrm{t}}^{*}=\frac{T_{\mathrm{t}}}{D}
$$

where $T_{\mathrm{t}}(\mathrm{h})$ is the transit time between two reservoirs and $D(\mathrm{~h})$ the duration of the flood event.

$$
S^{*}=\frac{S_{i}}{S_{\mathrm{tot}}}
$$

where $S_{i}\left(\mathrm{~km}^{2}\right)$ is the drained surface of one reservoir and $S_{\text {tot }}$ $\left(\mathrm{km}^{2}\right)$ the total catchment area.

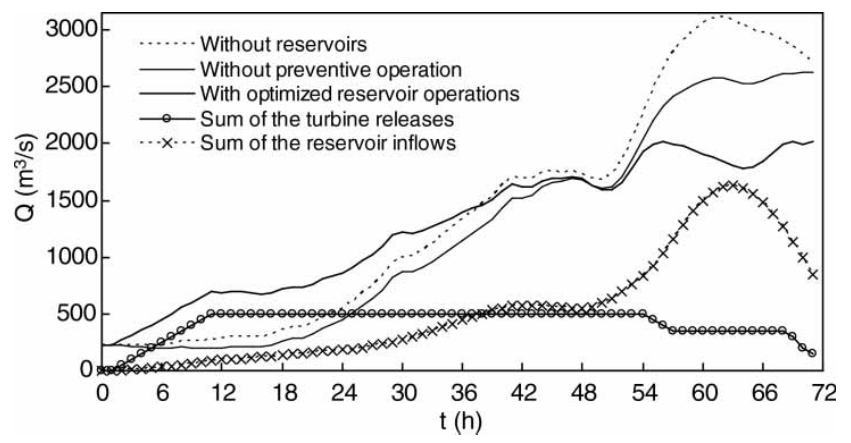

Figure 3 Example of a flood scenario: the flood hydrographs without reservoirs, without preventive turbine operations and with optimized operation of the reservoirs are compared and related to the total turbine releases from the reservoirs and the total inflows.
The following values are considered in this scenario: the installed turbine capacity for each hydropower scheme $Q_{\mathrm{T}}$ is $50 \mathrm{~m}^{3} / \mathrm{s}\left(Q_{\mathrm{T}}^{*}=0.016\right)$, the transit time between junctions is $T_{\mathrm{t}}=1 \mathrm{~h}\left(T_{\mathrm{t}}^{*}=0.014\right)$ and the width of the free overfall spillways is $30 \mathrm{~m}$. The flood peak without reservoirs is significantly higher than that with reservoirs, but without emptying operations before the flood peak. The normal reservoir routing effect without operational use of weather and hydrological predictions can reduce the flood peak by $16 \%$. If a flood forecast is available and the turbines are operated before the flood peak, the latter can be reduced by $34 \%$ (reduction of $1065 \mathrm{~m}^{3} / \mathrm{s}$ of $3112 \mathrm{~m}^{3} / \mathrm{s}$ in this example).

The turbine operations allow lowering of the reservoir water level and, therefore, to avoid the spillway operation during the flood event. The resulting discharge in the downstream river (with optimized operation of the reservoirs) is the sum of the discharge produced by the non-drained areas, and the discharge released through turbines and spillways.

\section{Influence of installed turbine capacity}

In this analysis, the drained areas for each reservoir as well as the installed turbine capacities are varied systematically. The transit time is set to $1 \mathrm{~h}$ and the width of the spillway to $30 \mathrm{~m}$. Figure 4 shows the evolution of the ratio between discharges at the catchment outlet with and without the presence of the multi-reservoir system.

The analysis indicates that the multi-reservoir system can reduce the flood peak to a maximum by $50 \%$ during flood events. This reduction highly depends on the drained surface of each reservoir. For example, a 25\% peak discharge reduction can be obtained if the total drained surface by all reservoirs is $30 \%$ of the entire catchment area $\left(S^{*}=0.03\right.$ in Figure 4).

The influence of the installed turbine capacity on the flood peak is shown for different values $Q_{\mathrm{T}}^{*}$ in Figure 4. $Q_{\mathrm{T}}^{*}=0$ corresponds to the case of a multi-reservoir system without installed turbines. The only reservoir routing effect is then obtained by the raise of the water level during spill over the crest of the spillway. Nevertheless, a maximum reduction of the flood peak of $12 \%$ can be obtained in the case of large drained areas $\left(S^{*}>0.05\right)$. With turbines having a sufficiently high installed capacity $\left(Q_{\mathrm{T}}^{*}>0.016\right)$, this means that they can release $16 \%$ of the peak flow without reservoirs, the flood protection effect would be three times greater and could reach a maximum of $36 \%$.

Finally, Figure 4 indicates that there is no further significant increase of the flood protection potential when the installed turbine capacity exceeds $Q_{\mathrm{T}}^{*}=0.024$. This can be explained by the high discharge released through the turbines before the peak flow. It can be even higher than the flood peak itself and produce damages before the flood. Of course, for high turbine capacities, the turbine opening could be limited in time in order to avoid such artificial flood peaks. 


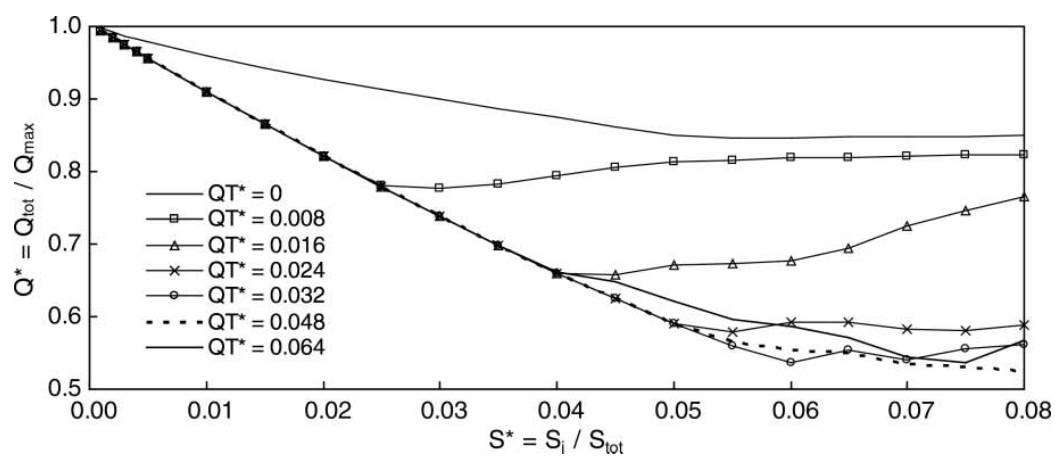

Figure 4 Influence of the normalized drained area $\left(S^{*}\right)$ on the maximum discharge at catchment outlet $\left(Q^{*}\right)$, as a function of the normalized installed turbine capacity $\left(Q_{\mathrm{T}}^{a} s t ;\right)$. $Q_{\max }=3100 \mathrm{~m}^{3} / \mathrm{s}$ is the maximum discharge at the catchment outlet without reservoirs.

\section{Influence of transit time between junctions}

The influence of the transit time between the junctions where the lateral rivers downstream of the reservoirs join the main valley was analysed. The result obtained is the flood protection potential for several spatial distributions of the reservoirs. Figure 5 presents the flood protection potential as a function of the drained areas by the reservoirs and transit times between the junctions. An installed turbine capacity of $Q_{\mathrm{T}}^{*}=0.016$ and a width of the spillways of $30 \mathrm{~m}$ was considered. $T_{\mathrm{t}}^{*}=t_{\mathrm{t}} / D$ is the ratio between the transit time and the duration of the flood event.

The influence of the drained area by each reservoir on the reduction of the peak flow is significant, but the highest effect is obtained when the reservoirs are located as close as possible to the catchment outlet. If the transit time is smaller than $T_{\mathrm{t}}^{*}=0.014$, the flood protection potential is maximum and reaches $35 \%$ of the peak flow reduction for a total drained area of $40 \%$. For higher transit periods $\left(T_{\mathrm{t}}^{*}>0.084\right)$, the reservoir located further from the catchment outlet has only a small protection effect. Therefore, the maximum reduction of the flood peak is only $18 \%$ even if $80 \%$ of the total area is drained by the reservoirs.

\section{Influence of spillway width}

In Figure 6, the width of the ungated crested spillway has been varied between $10 \mathrm{~m}$ and $150 \mathrm{~m}$, for an installed turbine capacity of $Q_{\mathrm{T}}^{*}=0.016$ and a transit time of $T_{\mathrm{t}}^{*}=0.014$.
For drained areas up to $S^{*}=0.03$, the width of the spillways has no influence. In fact, the turbine operations before the flood peak are sufficient to avoid any overtopping of the reservoirs and consequently spillways functioning during floods. For high drained areas by the reservoirs $\left(S^{*}>0.03\right)$, the turbine operations cannot avoid the functioning of the crested spillway. Therefore, the flood protection potential is directly related to the width of the spillway crest. The smallest width of the spillways studied $(B=10 \mathrm{~m})$ allows to reduce the flood peak by more than $45 \%$ (Figure 6). Spillways with wide crests do not store water during the overtopping of the reservoir, because high discharges are released with moderate head sites. On the other hand, spillways with narrow crests only release a limited discharge due to reservoir routing effects, but by significantly increasing the water level in the reservoir. Thus, the dam height would have to be increased accordingly.

\section{Influence of other parameters}

If the initial filling rate of the reservoir varies, similar results are obtained such that the installed turbine capacity varies. A high installed turbine capacity allows lowering of the reservoir level rapidly, which corresponds to a sufficient reservoir storage capacity before a flood event. Furthermore, the increase of rainfall intensity and total precipitation volume has the same effect as varying the drained area of the reservoirs. Finally, the variation of

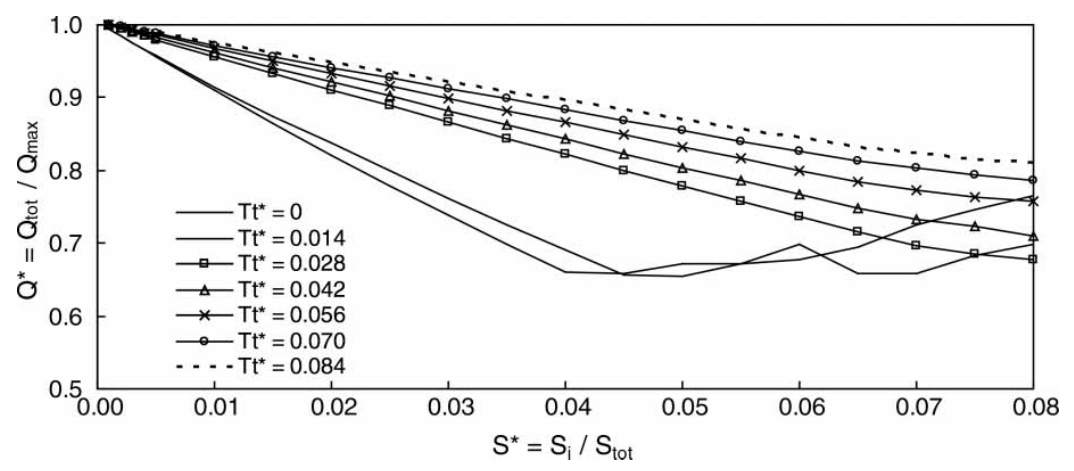

Figure 5 Influence of the drained area by the reservoirs $\left(S^{*}\right)$ and transit time $\left(T_{\mathrm{t}}^{*}\right)$ on the flood peak at catchment outlet $\left(Q^{*}\right)$. $Q_{\max }=3100 \mathrm{~m}^{3} / \mathrm{s}$ is the maximum discharge at the catchment outlet without reservoirs. 


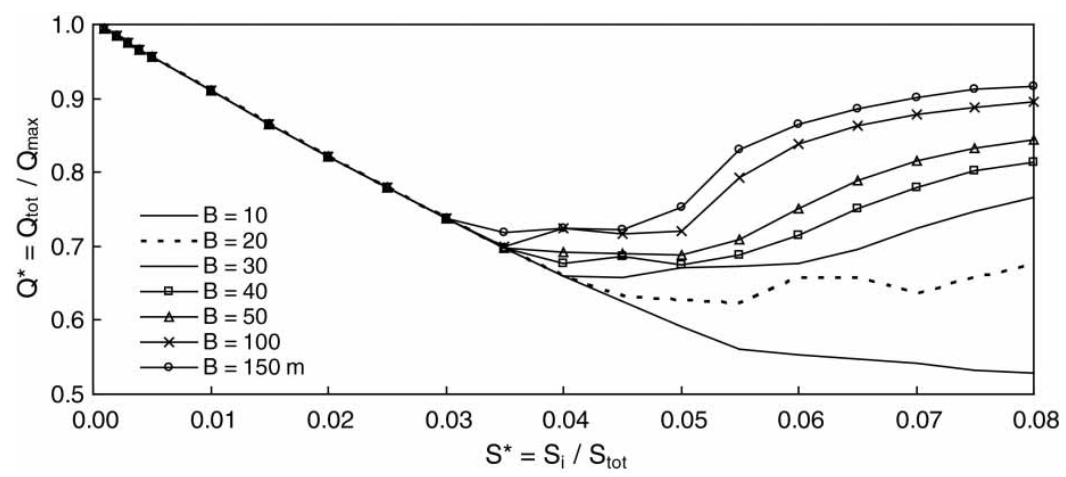

Figure 6 Influence of the drained area by the reservoirs $\left(S^{*}\right)$ and width of the spillway $(B)$ on the maximum discharge at catchment outlet $\left(Q^{*}\right) . Q_{\max }=$ $3100 \mathrm{~m}^{3} / \mathrm{s}$ is the maximum discharge at the catchment outlet without reservoirs.

the width of the spillway allows assessing the influence of any changes in the emergency rules of the water release structures at the dams.

\section{Application of the methodology at the Rhone River basin}

\section{Description of the catchment area}

The Rhone River basin upstream of Lake Geneva is located in the Swiss Alps with a total area of $5521 \mathrm{~km}^{2}$ (Figure 7). Numerous hydropower schemes with large reservoirs and complex water transfer systems are located in the catchment area (Table 3). The total storage capacity of all the reservoirs is $1200 \mathrm{Mio} \mathrm{m}^{3}$, and their total drained area is $1430 \mathrm{~km}^{2}$, which represents $26 \%$ of the total catchment area. The total installed turbine capacity is $320 \mathrm{~m}^{3} / \mathrm{s}$, which is significant when compared with the 100 years flood peak of approximately $1400 \mathrm{~m}^{3} / \mathrm{s}$ at the catchment outlet.

Influence of the existing multi-reservoir system of the discharge at the catchment outlet

Based on the theoretical approach presented before, an optimization model was developed in order to have a decision-making tool for the determination of the optimal use of turbines and gates of the existing reservoirs in the Rhone River upstream of Lake Geneva during the floods. The optimization is coupled with a hydrological simulation model for the prediction of the inflows into the reservoirs and the discharges at various check points in the catchment area.

The observed flood event of October 2000 was approximately a 100-year event and caused severe damages in the Rhone River valley (Raboud et al. 2001). Even without coordinated and optimized turbine operations, the multi-reservoir system reduced flood peak in the Rhone River and significantly limited the flood damages (Figure 8). The reservoirs were able to reduce the flood peak at the catchment outlet by $10 \%$. Nevertheless, a total discharge of $223 \mathrm{~m}^{3} / \mathrm{s}$ was released during the flood peak from the reservoirs through the turbines and spillways. The flood peak could have been further reduced by optimized turbine operations.

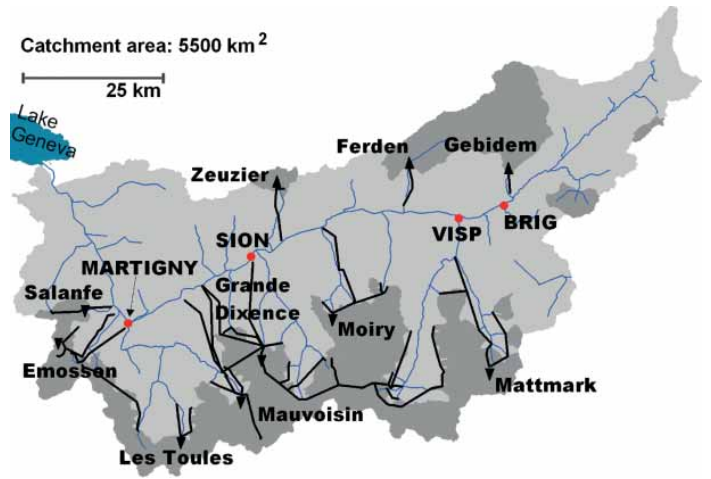

Figure 7 Rhone River basin upstream of Lake Geneva with the 10 major hydropower schemes. The dark grey areas are the drained surfaces by the reservoirs.

If the turbine operations could have been based on a perfect $72 \mathrm{~h}$ hydrological forecast (optimum), the total released discharge would have been reduced by $70 \mathrm{~m}^{3} / \mathrm{s}$ and therefore the flood peak in the Rhone River limited to $1194 \mathrm{~m}^{3} / \mathrm{s}$ instead of $1450 \mathrm{~m}^{3} / \mathrm{s}$ without reservoirs. This corresponds to a reduction of $21 \%$ of the flood peak. Almost the same reduction could have been achieved with an operational hydrological forecast (Figure 8) that means updating the optimization procedure every $12 \mathrm{~h}$ when a new forecast is available.

Since 2006, the presented optimization methodology is fully implemented in the MINERVE flood management tool. In September 2006, a flood alarm was given by the weather forecast and the required decisions regarding the preventive reservoir emptying could be handled successfully (Jordan 2007, Jordan et al. 2008). At the moment, the flood management tool is enhanced with probabilistic weather forecast (Garcia et al. 2009).

\section{Conclusion}

A methodological approach for the optimization of the flood protection potential of a multi-reservoir system in complex catchment areas was presented. The most relevant parameters of such complex systems regarding their effect on flood peaks could be highlighted. The model is able to consider up to 10 
Table 3 Technical characteristics of the 10 major HPP of the Rhone River catchment area.

\begin{tabular}{|c|c|c|c|c|c|c|c|}
\hline $\begin{array}{l}\text { Hydropower } \\
\text { scheme }\end{array}$ & $\begin{array}{l}\mathrm{Nb} \text { reservoirs and } \\
\text { compensation basins }\end{array}$ & $\begin{array}{l}\text { Storage } \\
\text { volume } \\
\left(\mathrm{Mm}^{3}\right)\end{array}$ & $\begin{array}{l}\text { Reservoir area } \\
\left(\mathrm{km}^{2}\right)\end{array}$ & $\begin{array}{c}\text { Drained area } \\
\left(\mathrm{km}^{2}\right)\end{array}$ & $\begin{array}{c}\mathrm{Nb} \\
\text { powerhouses }\end{array}$ & $\begin{array}{c}\text { Total installed } \\
\text { capacity at pumps } \\
\left(\mathrm{m}^{3} / \mathrm{s}\right)\end{array}$ & $\begin{array}{c}\text { Total installed } \\
\text { capacity at turbines } \\
\left(\mathrm{m}^{3} / \mathrm{s}\right)\end{array}$ \\
\hline $\begin{array}{l}\text { Grande } \\
\text { Dixence }\end{array}$ & 6 & 401 & 3.73 & 384 & 8 & 42.7 & 130.2 \\
\hline Emosson & 4 & 225 & 3.13 & 106 & 4 & 18 & 29 \\
\hline Mauvoisin & 2 & 206 & 2.14 & 169 & 2 & - & 28.8 \\
\hline Mattmark & 2 & 100 & 1.76 & 94 & 3 & 9.5 & 19 \\
\hline Moiry & 4 & 77 & 1.05 & 167 & 6 & 9 & 12.9 \\
\hline Zeuzier & 2 & 50 & 0.8 & 26 & 2 & - & 11 \\
\hline Salanfe & 1 & 40 & 1.76 & 46 & 1 & - & 4.8 \\
\hline Les Toules & 2 & 20 & 0.57 & 74 & 2 & - & 10 \\
\hline Gebidem & 1 & 5.8 & 0.19 & 199 & 1 & - & 55 \\
\hline Ferden & 1 & 1.9 & 0.09 & 137 & 1 & - & 21.3 \\
\hline Total & 25 & 1126.7 & 15.55 & 1402 & 30 & 79.2 & 321.95 \\
\hline
\end{tabular}
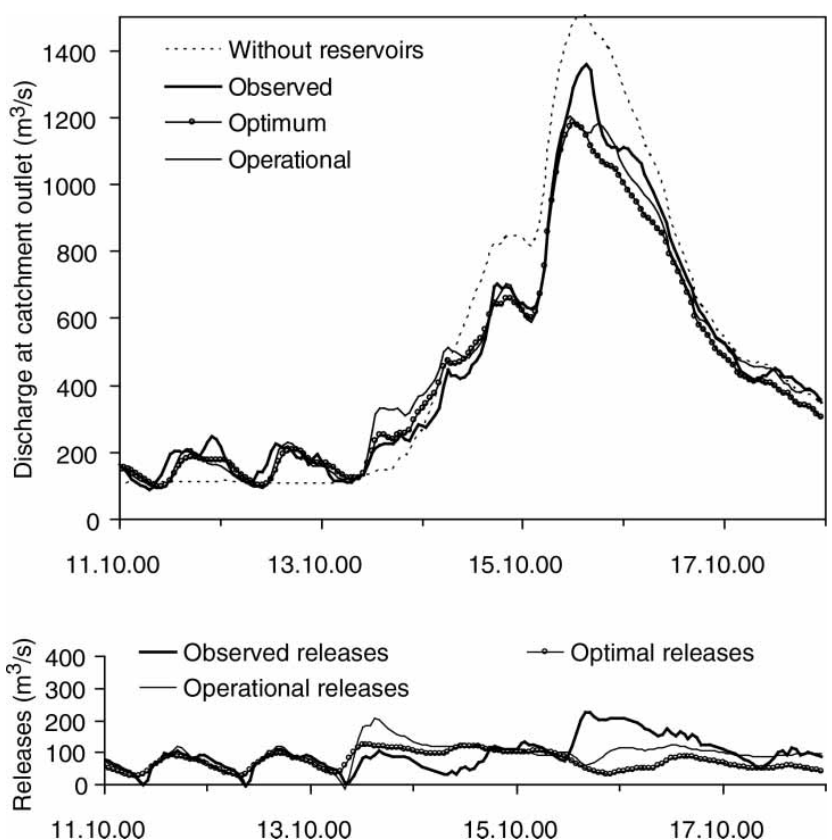

Figure 8 Flood hydrographs during the flood event of October 2000 The hydrographs without reservoirs, without preventive turbine operations and with optimized turbine operations are compared.

hydropower schemes with large reservoirs equipped with free surface spillways and high head turbines. Their flood retention effect is considered and optimized in order to minimize the flood peaks downstream in the main valley.

The simulation carried out on an idealized and parameterized catchment area indicates that flood peaks can be reduced by $40 \%$ for systems, where the drained area by the reservoirs represents $30-50 \%$ of the total catchment area. Under such conditions, a total installed turbine capacity of $16 \%$ of the flood peak is already sufficient to achieve this maximum discharge reduction.

If a certain number of large reservoirs are located in the catchment area, they reduce the flood peak downstream even without water release before the flood event. Nevertheless, based on hydrological forecasts, the inflows in the reservoirs can be predicted. Then, the preventive water released through the turbines can be optimized. Thus, flood protection potential of reservoirs can be increased significantly and an optimum reduction of the flood peaks can be achieved without reducing energy generation of the powerhouses.

The approach tested on a theoretical model was applied to the Upper Rhone River basin, where 10 hydropower schemes with large reservoirs are located. The integrated flood management system MINERVE was developed for this catchment area that allows to predict and simulate floods in real time, since 2006 . The flood event of October 2000 was analysed with the help of the integrated MINERVE tool. It was shown that in this catchment area, where $26 \%$ of the surface is drained by the reservoirs and where the total installed turbine capacity represents $23 \%$ of the 100-years flood peak, the observed reduction of the peak flow in 2000 could have increased by three times to almost $20 \%$ if the turbines had been operated in an optimized way. In September 2006, the optimization methodology could be successfully tested at a forecasted flood event (Jordan 2007).

\section{Acknowledgements}

The MINERVE project is funded by the Swiss Federal Office for the Environment (FOEN) and the Canton of Valais. The precipitation and temperature forecasts are provided by the Swiss Weather Services.

\section{References}

Ahmad, S. and Simonovic, S., 2000. System dynamics modeling of reservoir operations for flood management. Journal of Computing in Civil Engineering, 14 (3), 190-198. 
Boillat, J.-L., 2005. L'influence des retenues valaisannes sur les crues - Le projet MINERVE, In: A. Schleiss, ed. Proceedings of the Conférence sur la recherche appliquée en relation avec la 3e Correction du Rhône - Nouveaux développements dans la gestion des crues., Martigny: Communication 21 of the Laboratory of Hydraulic Constructions, Ed. A. Schleiss, 87-101.

Boillat, J.-L., Dubois, J., Schleiss, A., and Jordan, F.M., 2002. Flood modelling and prevention in the Rhone basin upstream of Lake Geneva, Proceedings of the international conference on flood estimation, 6-8 March, Berne, 389-395.

Buergi, T., 2002. Wasserstands- und Abflussvorhersagen für den Rhein. Wasser Energie Luft, 94 (7/8), 199-205.

Cheng, C.-T. and Chau, K.W., 2004. Flood control management system for reservoirs. Environmental Modelling and Software, 19, 1141-1150.

De Roo, A.P.J., et al., 2003. Development of a European flood forecasting system. Intl. J. River Basin Manag, 1 (1), 49-59.

Drabek, U., et al., 2002. Das Durchflussprognosesystem HYSIM als Teil des EPV-Energiewirtschaftliches Planungssystem Verbund, Proc. Internationales Symposium Moderne Methoden und Konzepte im Wasserbau, Mitteilungen der Versuchsanstalt für Wasserbau, Hydrologie und Glaziologie Nr. 175, ETH, Zürich, 7-9 October, Zürich, 301-311.

Eschenbach, et al., 2001. Goal programming decision support system for multiobjective operation of reservoir systems. Journal of Water Resources Planning and Management, 127 (2), 108-120.

Garcia, J., et al., 2009. Ensemble hydrological forecasts for the Upper Rhone River basin, Proc. 33th IAHR Congress, Vancouver, 9-14 August, CD-Rom.

Jain, S., Das, A., and Srivastava, D., 1999. Application of ANN for reservoir inflow prediction and operation. Journal of Water Resources Planning and Management, 125 (5), 263-271.

Jordan, F., 2007. Modèle de prévision et de gestion des crues optimisation des opérations des aménagements hydroélectriques à accumulation pour la réduction des débits de crues. Ph.D. Thesis No 3711, Ecole Polytechnique Fédérale
Lausanne, $261 \mathrm{pp}$ and Communication 29 of the Laboratory of Hydraulic Constructions, Ed. A. Schleiss.

Jordan, F., et al., 2005. Real-time flood management by preventive operations on multiple alpine hydropower schemes, Proceedings of the 31th IAHR Congress, 11-17 September, Seoul, 3235-3245.

Jordan, F., et al., 2006a. Modell zur Hochwasser Vorhersage und Hochwassermanagement der Rhone, Proc. ÖWAW-Seminar, Hochwasservorhersage, Erfahrungen, Entwicklungen und Realität, 19-20 October, Wiener Mitteilungen Band 199, ÖWAV, Vienna, 103-118.

Jordan, F., et al., 2006b. Prévision et gestion des crues par operations preventives sur les retenues alpines, Proc. XXIIe Congrès des Grands Barrages, 18-23 June, Barcelona, Q87 R34, 499-510.

Jordan, F., et al., 2008. Flood forecast and flood management model, Interpraevent 2008, Dornbirn, Vorarlberg, Austria, 26-30 May, Conference Proceedings, Vol. 1, 141-151.

Labadie, J.W., 2004. Optimal operation of multireservoir systems: state-of-the-art review. Journal of Water Resources Planning and Management, 130 (2), 93-111.

Raboud, P.-B., et al., 2001. Projet MINERVE-Modélisation de la contribution des bassins d'accumulation lors des crues en Valais. Wasser Energie Luft, 93 (11/12), 313-317.

Reszler, C., et al., 2006. Ein Ansatz zur Identifikation flächendetaillierter Abflussmodelle für die Hochwasservorhersage. Hydrologie und Wasserwirtschaft, 50 (H5), 220-232.

Schaefli, B., et al., 2005. A conceptual glacio-hydrological model for high mountainous catchments. Hydrology and Earth System Sciences Discussions, 2, 73-117.

Turcotte, R., et al., 2004. Distributed hydrological forecast for the management of public dams in Quebec. Canadian Journal of Civil Engineering, 31 (2), 308-320.

Yeh, W.W.-G., 1985. Reservoir management and operations models: a state-of-the-art review. Water Resources Research, 21 (12), 1797-1818.

Yeh, W.W.-G. and Becker, L., 1982. Multiobjective analysis of multireservoir operations. Water Resources Research, 18 (5), 1326-1336. 